\title{
Desenvolvimento de um calçado para joanete com ênfase estética: abordagem participativa e centrada no usuário
}

Development of a footwear for bunion with aesthetic emphasis: participatory and user centered approach

TAKAYAMA, Letícia; Bacharel em Design; Universidade Federal de Santa Catarina takayamaleticia@gmail.com

MERINO, Giselle S. A. D.; Doutora em Eng. Produção; Universidade Federal de Santa Catarina; Universidade da Região de Joinville

gisellemerino@gmail.com

MERINO, Eugenio A. D.; Doutor em Eng. Produção; Universidade Federal de Santa Catarina

merino@cce.ufsc.br

\section{Resumo}

O princípio do calçado é a proteção. No entanto, quando há divergências entre os calçados e os pés, o seu uso pode causar deformações como o joanete. Deste modo, a presente pesquisa teve como objetivo desenvolver um calçado para mulheres com joanete com ênfase na estética. A pesquisa apresentou duas Etapas. Na Etapa 1 foi realizada a Base Teórica. Na Etapa 2 ocorreu o Desenvolvimento pela abordagem participativa e centrada no usuário aplicada em questionários e entrevistas com dados posteriormente sintetizados em requisitos. Na sequência, foi elaborado o estudo das tendências para o verão 2018 com foco nos relatórios da WGSN. As alternativas foram geradas por ilustrações e protótipos. O modelo de sapatilha selecionado apresentou desenho curvilíneo, materiais elásticos e palmilha ampla, além de três propostas estéticas feitas com aviamentos e cores diferenciados que camuflaram o joanete. Como resultado, o checklist verificou a adequação do modelo de calçado aos requisitos.

Palavras Chave: Calçado. Joanete. Design Participativo. Design Centrado no Usuário.

\begin{abstract}
The principle of the footwear is protection. However, when there is a deviation between footwear and feet, its use can cause deformations such as bunions. Therefore, the present research aimed to develop a footwear for women with bunion that emphasizes the aesthetic. The research was presented in two Steps. In Step 1 the theoretical basis was created. The Step 2 was the Development using the participatory and user centered design approach applied in questionnaires and interviews that were synthesized into requirements. Next, the trend survey for summer 2018 was studied focusing on the WGSN reports. The alternatives were created using illustrations and prototypes. The chosen footwear was a ballerina flat with curvilinear design, elastic materials, wide insole and three aesthetic models made with different colors and materials that camouflaged the bunion. As a result, the checklist verified the suitability of the footwear model in comparison to the requirements.
\end{abstract}

Keywords: Footwear. Bunion. Participatory Design. User Centered Design. 


\section{Introdução}

A palavra calçado possui sua origem do latim calceus e significa um artefato para resguardar os pés do contato com o solo. Em seu princípio, o calçado foi criado para proteger os pés do ambiente externo e possibilitar a locomoção com redução de dores. No entanto, quando há grandes divergências entre o calçado e as características dos pés dos usuários, o seu uso pode causar alterações morfológicas nos pés, reduzir ou prejudicar a estabilidade postural do corpo, resultar em alterações neurofisiológicas, causar desiquilíbrio muscular e ajudar no desenvolvimento de pés mais sensíveis (GOONETILLEKE, 2012).

Deste modo, alguns dos problemas nos pés podem ser causados pelo uso de calçados inadequados, estas patologias podem ser caracterizadas como: dedos em garra, lesões no nervo, fascite plantar, lesões no tendão de Aquiles e outras deformidades como o joanete, por exemplo (GOLDCHER, 2009). Neste sentido, segundo Goonetilleke (2012), o problema mais comum de dificuldade na adaptação do calçado aos pés é o hálux valgo (joanete). Esta deformação causa o alargamento da região metatarsofalângica dos pés e dificulta o uso de calçados comuns.

Conforme a pesquisa de Case (2012), feita com 21.423 brasileiros entre 15 e 90 anos, o joanete acomete tanto homens quanto mulheres. Nesta pesquisa, cerca de $8,4 \%$ dos homens da amostra sofria com o joanete, enquanto as mulheres representaram $22,4 \%$ da população. Neste estudo, o autor também destacou que o uso prolongado de calçados inadequados para joanete foi um dos problemas mais frequentes e utilizado como justificativa para a maior porcentagem desta deformação entre as mulheres.

Neste contexto, pessoas que possuem joanete sofrem com a falta de modelos de calçados que se adaptam às suas necessidades e possuam a estética desejada. Deste modo, o Design Participativo aliado ao Design Centrado no Usuário pode ajudar a entender melhor as necessidades destes usuários e desenvolver calçados mais apropriados.

Sendo assim, a presente pesquisa teve como objetivo desenvolver um calçado para mulheres com joanete com o intuito de adequá-lo aos requisitos estéticos dos usuários com base no Design Participativo, Design Centrado no Usuário e tendências para o verão 2018.

\section{Procedimentos Metodológicos}

A presente pesquisa foi dividida em duas Etapas. A Etapa 1 foi composta pela Base Teórica em buscas sobre calçados, joanete, estética, Design Participativo e Design Centrado no Usuário. Esta etapa foi elaborada pela análise de estudos publicados na língua portuguesa e inglesa, em livros e bases de dados em bibliotecas digitais como: Portal de Periódicos CAPES, Science Direct, ResearchGate e Google Scholar. Nas buscas foram utilizadas as palavras: "calçado/ shoe", "joanete/ bunnion", "estética/ aesthetic", "Design Participativo/Participatory Design" e "Design Centrado no Usuário/ User Centered Design".

A Etapa 2, denominada de Desenvolvimento, possuiu natureza aplicada e objetivos exploratórios, pois envolveu a prática de ferramentas e técnicas a fim de permitir maior familiaridade com o tema de pesquisa. Deste modo, foram elaborados questionários online e entrevistas presenciais que objetivaram abordar o Design Participativo e Centrado no Usuário pela análise quantitativa dos dados sobre mulheres com joanete e análise qualitativa das suas características e necessidades relacionadas aos calçados. 
Na sequência, foi gerada uma tabela dos requisitos do produto e do usuário com base na análise dos questionários e entrevistas, levando em consideração os aspectos de saúde, segurança e estética do calçado.

Devido ao enfoque estético do projeto, foi elaborado um estudo de tendência com ênfase no verão de 2018 com base nos relatórios da WGSN (Worth Global Style Network), considerada uma grande autoridade de previsão de tendências mundiais. A tendência central para o verão de 2018 possuiu quatro temáticas menores e pela análise de cada vertente, foi escolhida a temática que mais se relacionou com os usuários pelas conexões de culturas, coletivos e ideias, também associadas a abordagem participativa e centrada no usuário.

Em seguida foi feito o desenvolvimento do calçado para joanete. Para sintetizar, foi elaborado um brainstorm, caracterizado como uma técnica criativa para auxiliar na geração de ideias. Em seguida, as alternativas dos modelos de calçado foram geradas por ilustrações manuais e protótipos funcionais com técnicas e materiais tradicionais utilizados na fabricação de calçados. Devido a variedade de modelos de calçado que foram adequados aos requisitos de projeto, foi escolhido um calçado básico do tipo sapatilha e a partir deste modelo foram geradas três alternativas com cores e aviamentos diferentes, pela abordagem temática da tendência selecionada. Posteriormente, estas alternativas foram materializadas em protótipos funcionais e analisadas em uma tabela de checklist para comparar as suas características com os requisitos, pela ênfase na estética.

\section{Etapa 1 - Base Teórica}

\subsection{0 joanete e a estética dos calçados}

O joanete ou hálux valgo (Figura 1), é uma deformação óssea que ocorre pelo desalinhamento da articulação metatarsofalângica do grande dedo do pé. Como causa, o dedão se desloca sobre os outros dedos causando o alargamento do pé e prejudicando várias articulações do corpo (VARELLA, 2014).

Figura 1 - Diferença entre o pé normal e pé com hálux valgo

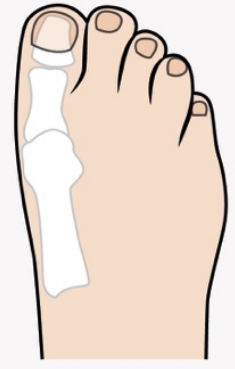

Pé normal

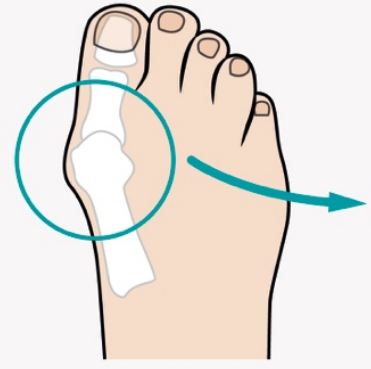

Pé com hálux valgo

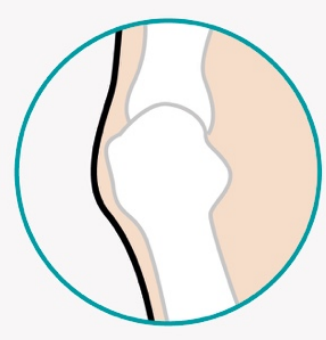

Detalhe do hálux valgo

Fonte: Os autores

O joanete possui como um dos fatores de surgimento e agravamento o uso de calçados de salto alto ou com ponta estreita, além de outros fatores congênitos, traumáticos, neurológicos ou inflamatórios. Deste modo, a falta de modelos para pés com joanete que sejam confortáveis e possuam estética agradável faz com que os usuários optem pelo uso de calçados inadequados causando dores, desconforto e o aumento da deformidade (GOLDCHER, 2009). 
Neste sentido, pesquisas sobre a estética dos calçados é fundamental para elaborar calçados que possuam características estéticas, ergonômicas e funcionais adequadas aos usuários. Para Goonetilleke (2012), um fator comum entre os calçados confortáveis e desconfortáveis é a sua estética. Segundo o autor, a decisão do usuário em usar ou não determinado calçado depende da sua satisfação visual, o que faz com que o formato e o estilo sejam tão importantes quanto os elementos funcionais do calçado.

A palavra estética vem do grego aísthesis, que significa sensação, sentimento. Diferentemente da poética, que já parte de gêneros artísticos constituídos, a estética analisa o complexo das sensações e dos sentimentos, investiga sua integração nas atividades físicas e mentais do homem, debruçando-se sobre as produções (artísticas ou não) da sensibilidade, com o fim de determinar suas relações com o conhecimento, a razão e a ética (ROSENFIELD, 2006).

A estética está relacionada com as tendências compostas de elementos como forma, proporção, cor, materiais, acabamentos e texturas para criar um visual expresso em sensações, personalidade e distinção (DORR, 2017).

Segundo Souza e Held (2011), a estética também pode ser descrita como "a ciência que trata do belo e do sentimento que desperta em nós beleza". Deste modo, no consumo de bens materiais, os conceitos de beleza deixam de ser atribuídos ao próprio objeto para fazer parte da estética do indivíduo que o usa. Neste sentido, o estudo da estética no desenvolvimento de calçados é importante para proporcionar produtos mais adequados às necessidades físicas e mentais dos usuários.

\subsection{Design Participativo e Design Centrado no Usuário no desenvolvimento de calçados}

O envolvimento dos usuários no processo de design é definido como Design Participativo. Ele abrange várias práticas que têm como objetivo coletar, analisar e ajudar no desenvolvimento de projetos voltados para os usuários. O Design Participativo também pode ser visto como um complemento do Design Centrado no Usuário, devido a estas práticas participativas e foco nas suas necessidades. Como resultado, o Design Participativo e o Design Centrado no Usuário podem reduzir os erros de projeto e melhorar a aceitação e satisfação do usuário (CRABTREE, 2003; CAMARGO; FAZANI, 2014; ENDSLEY; BOLTÉ; JONES, 2003).

A abordagem participativa envolve os usuários diretamente e ativamente no processo de design (CRABTREE, 2003). Já a abordagem do design centrado no usuário coloca o usuário no centro de cada etapa, como forma de entender suas capacidades e desejos, criando produtos reais, para necessidades reais (MERINO, 2016). Deste modo, o Design Participativo e o Design Centrado no Usuário interligam-se como complemento um do outro devido ao pensamento voltado para o usuário por meio de práticas de coleta e tratamento de dados.

No design de calçados, principalmente para pés com algum tipo de necessidade especial, como joanete por exemplo, as abordagens participativa e centrada no usuário trazem a associação da ergonomia e funcionalidade do calçado com a estética e preferência dos usuários.

Entre todos os dispositivos da grande aparelhagem, o calçado é dos mais difíceis de se realizar, tendo que associar a estética e funcionalidade. Deve agradar ao paciente e adaptar-se ao pé patológico, muitas vezes dismórficos e cujo dinamismo não respeita necessariamente a biomecânica habitual. Além disso, não existe método de controle científico. Os únicos critérios de avaliação são a apreciação do paciente e o desgaste do calçado (GOLDCHER, 2009). 
Deste modo, é importante que a escolha do calçado seja bem avaliada para que os usuários tenham melhor aceitação em relação ao seu modelo e estética. No entanto, Tyrrell e Carter (2009) enfatizaram que é o usuário quem decide o uso o não uso do calçado. Este poder de decisão, chamado de empoderamento do usuário, pode ser entendido como a retomada do conhecimento, habilidades e decisões para o próprio indivíduo. Sendo assim, o alinhamento das características estéticas, físicas e ergonômicas deve ser bem analisado para adequar-se ao usuário, garantindo que este realmente use o calçado e desfrute de seus benefícios.

\section{Etapa 2 - Desenvolvimento}

\subsection{Abordagem participativa e centrada no usuário para os requisitos de projeto}

Com o intuito de entender melhor os usuários e desenvolver calçados mais apropriados para as suas necessidades, a abordagem participativa e centrada no usuário ocorreu pelo uso de questionários e entrevistas com mulheres que possuíam joanete entre os meses de outubro e novembro de 2016. Este estudo, apresentado em Takayama, Merino e Merino (2017), teve como objetivo gerar requisitos com base nos dados analisados dos questionários e entrevistas para a elaboração de um modelo de calçado para mulheres com joanete.

\subsubsection{Questionários}

O questionário foi aplicado em uma plataforma online e obteve 42 respostas de mulheres com média de 20 a 49 anos. Mais da metade das participantes (69\%) responderam que possuíam dificuldades em encontrar calçados por causa do joanete, sendo que a maioria (88\%) nunca utilizou calçados especiais para joanete. Do mesmo modo, os questionários também mostraram que a aparência é um fator importante a ser considerado, uma vez que $86 \%$ das participantes se consideravam vaidosas e $76 \%$ delas já usaram um calçado desconfortável levando em consideração apenas a sua estética.

$\mathrm{Na}$ continuação do questionário foram elaboradas perguntas sobre quais modelos de calçado eram preferidos pelas participantes. Dentre as respostas, o tênis (81\%) e a sapatilha (57\%) foram os mais mencionados, seguidos da bota (48\%), chinelo (43\%), sandália (38\%), mocassim (14\%), oxford (14\%) e sapato de salto (14\%), conforme a Figura 2.

Figura 2 - Modelos de calçado mais usados

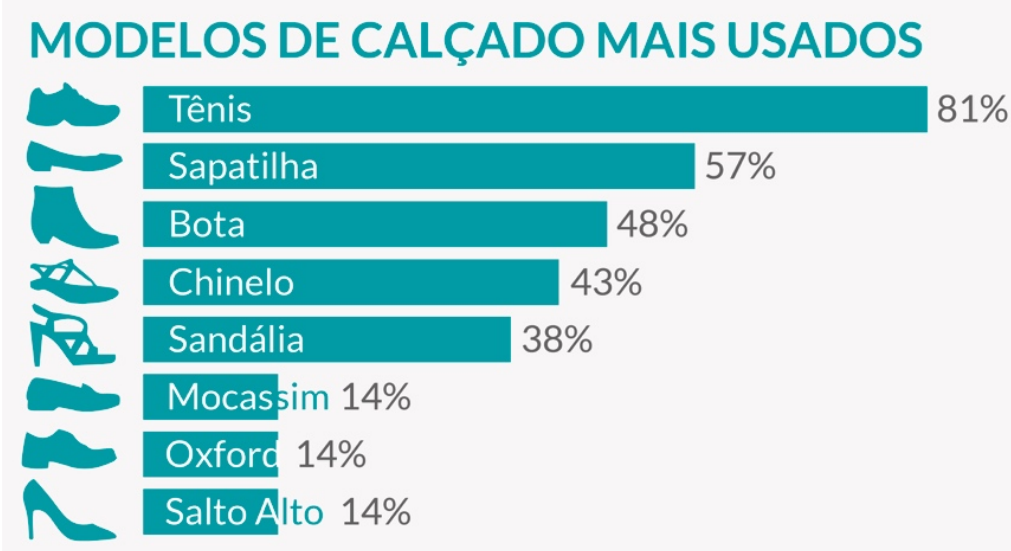

Fonte: Os autores 


\subsubsection{Entrevistas}

Foram elaboradas entrevistas semiestruturadas com 8 mulheres de 23 a 84 anos. As entrevistas foram realizadas de forma presencial e nela foram elaboradas perguntas sobre 0 tempo de desenvolvimento do joanete, sua natureza, tipo de calçado que costuma usar e os problemas com o conforto nos pés.

Pelas entrevistas, quatro das participantes possuíam joanete por pré-disposição genética, três possuíam joanete pelo uso prolongado de calçados inadequados e uma delas desenvolveu o joanete devido ao diabetes, como doença degenerativa. As entrevistadas relataram dores na região do joanete, sendo que algumas delas também possuíam inchaço nos pés.

Os modelos de calçados mais usados pelas entrevistadas foram a sapatilha, o chinelo, o tênis e a bota e as marcas de calçado mais usadas foram a Usaflex, Piccadilly e Comfortflex. Também foi verificado que o verão foi a estação do ano considerada a mais difícil de encontrar calçados adequados para o joanete devido a oferta de modelos mais abertos, que acabam machucando a lateral dos pés ou causando constrangimento por causa da aparência do joanete.

\subsubsection{Requisitos de Projeto}

Com base na análise dos questionários e entrevistas, foram gerados requisitos do produto e do usuário levando em conta aspectos de saúde, segurança e estética, como mostra a Tabela 1.

Tabela 1: Requisitos do Usuário e do Produto

\begin{tabular}{|c|c|c|}
\hline & REQUISITOS DO USUÁRIO & REQUISITOS DO PRODUTO \\
\hline SAÚDE & $\begin{array}{l}\text { Ter a base correspondente à largura do pé e } \\
\text { calcanhar; } \\
\text { Reduzir ou evitar o crescimento do joanete; } \\
\text { Não possuir áreas que possam causar ulcerações } \\
\text { nos pés; } \\
\text { Adequar a distribuição de peso do corpo sobre a } \\
\text { palmilha; } \\
\text { Possuir bom calce sem pressões excessivas; }\end{array}$ & $\begin{array}{l}\text { Possuir o salto baixo (entre } 1 \mathrm{~cm} \text { a } 4 \mathrm{~cm} \text { ) para } \\
\text { evitar o agravamento do joanete; } \\
\text { Possuir tecido elástico na lateral do joanete para } \\
\text { não pressionar esta área; } \\
\text { Ser leve, por volta de } 500-600 \mathrm{~g} \text {, para não } \\
\text { prejudicar na marcha demandando esforços } \\
\text { desnecessários na caminhada; } \\
\text { Possuir base larga; }\end{array}$ \\
\hline SEGURANÇA & $\begin{array}{l}\text { Ser adaptável a diferentes larguras de pés e } \\
\text { tamanhos de joanete; } \\
\text { Promover estabilidade durante a marcha; } \\
\text { Permitir o ajuste fácil e seguro; }\end{array}$ & $\begin{array}{l}\text { Não possuir costuras internas na área do joanete } \\
\text { a fim de evitar zonas de fricção; } \\
\text { Possuir solas semirrígidas de material } \\
\text { antiderrapante, como borracha ou poliuretano, a } \\
\text { fim de absorver choques do pé contra o solo; } \\
\text { Possuir solado que possa se adaptar a diferentes } \\
\text { tipos de solo; }\end{array}$ \\
\hline ESTÉTICA & $\begin{array}{l}\text { Possuir estética agradável adequada às } \\
\text { tendências; } \\
\text { Camuflar o joanete para evitar o } \\
\text { constrangimento causado por esta deformação; } \\
\text { Ser um modelo de tênis, sapatilha ou bota, para } \\
\text { ter maior aceitação dos usuários. }\end{array}$ & $\begin{array}{l}\text { Possuir palmilha macia e confortável; } \\
\text { Ter propriedades térmicas adequadas, que } \\
\text { mantém os pés secos e levemente aquecidos; } \\
\text { Apresentar boa flexibilidade e aderência com a } \\
\text { superfície de apoio. }\end{array}$ \\
\hline
\end{tabular}

Fonte: Os autores

Como recorte para a presente pesquisa, foram abordados os requisitos do usuário em relação à estética, descritos como:

- Possuir estética agradável adequada às tendências; 
- Camuflar o joanete para evitar o constrangimento causado por esta deformação;

- Ser um modelo de tênis, sapatilha ou bota, para ter maior aceitação dos usuários.

\subsection{Pesquisa de tendências verão 2018}

Para ajudar a cumprir o requisito de possuir estética agradável adequada às tendências, foi elaborada um estudo de tendência com base nos relatórios da WGSN, considerada uma grande autoridade de previsão de tendências mundiais (WGSN, 2016).

Para a presente pesquisa, foram consideradas as tendências para o verão de 2018, publicados no website da WGSN entre os meses de maio e setembro de 2016. Esta estação foi escolhida por ser considerada a época do ano na qual as pessoas com joanete possuíam maior dificuldade em encontrar calçados devido aos modelos abertos como sandálias e chinelos que causavam constrangimento devido a deformação dos pés.

Para o verão de 2018, a WGSN apresentou o grande tema States Of Mind (Estado de Espírito) que possuía quatro temáticas: Slow Futures (Futuros Lentos), Kindship (Parentesco), Youth Tonic (Juventude Tônica) e Psychotropical (Psicotropical).

Levando em consideração os usuários de calçados para mulheres com joanete, a temática escolhida foi o Kindship, pois estava relacionada ao respeito e conexões entre culturas, coletivos e ideias no sentido de comunidade, assim como a própria abordagem participativa e centrada no usuário da presente pesquisa.

O conceito da temática Kindship abordou um novo olhar sobre a beleza definido pela presença de um espírito livre com a aplicação de aspectos mais artísticos e artesanais permeados por detalhes delicados e adornos personalizados. Ele foi inspirado na expansão das novas rotas de comunicação do mundo, que resultou na mistura de influências culturais (WGSN, 2016).

A paleta cromática para o Kindship (Figura 3) possuiu cores marcantes como vermelhos e amarelos contrabalanceados com cores mais calmas em tons de azul e verde. Esta paleta também harmonizou com tons mais escuros e neutros, o que concedeu maior versatilidade nas composições de cores (WGSN, 2016).

Figura 3 - Paleta cromática Kindship

\begin{tabular}{|c|c|c|c|c|}
\hline ROSA ARGILA & CORAL & CARMIM & $\begin{array}{l}\text { LARANJA } \\
\text { ABÓBORA }\end{array}$ & $\begin{array}{l}\text { PIMENTA } \\
\text { DOURADA }\end{array}$ \\
\hline $\begin{array}{l}\text { VERMELHO } \\
\text { BETERRABA }\end{array}$ & $\begin{array}{l}\text { VERMELHO } \\
\text { AMORA }\end{array}$ & AZUL SÁBIO & $\begin{array}{c}\text { AZUL } \\
\text { HORIZONTE }\end{array}$ & AZUL MARUJO \\
\hline CORES CENTRAIS & PRET & $\mathrm{NHO}$ & TRAIS & AREIA BRANCA \\
\hline
\end{tabular}

Fonte: Os autores com base em WGSN, 2016

Nesta paleta cromática, os tons quentes que significaram otimismo e calor foram inspirados no pôr do sol. Já o tom rosa foi uma cor mais sofisticada e feminina que teve influência de tons mais argilosos que se remetem ao artesanato. Os tons de vermelho foram elementos fortes e versáteis nesta paleta, escolhidos com base nos tons de frutas e vegetais, como a amora e a beterraba. Os azuis foram inspirados em tons que se remetem ao mar e estavam relacionados às rotas que conectam pessoas ao redor do mundo. Estas cores também faziam contrabalanço com 
as outras cores da paleta pois são mais frias e podem ser aplicadas em gêneros e culturas diferentes, mas com o mesmo significado. Por fim, o preto marinho e o branco arenoso foram cores chave mais neutras para a temática Kindship (WGSN, 2016).

Em relação ao design de calçados e acessórios, a temática Kindship possuiu uma mistura de superfícies e cores, que foram escolhidas com base em diferentes culturas do mundo todo. Os estilos locais foram compartilhados e tendências globais foram reinterpretadas com nuances da cultura local (WGSN, 2016). Neste sentido, algumas tendências em relação aos detalhes nos calçados para o verão 2018 foram representadas na Figura 4.

Figura 4 - Tendências de detalhes nos calçados no Kindship

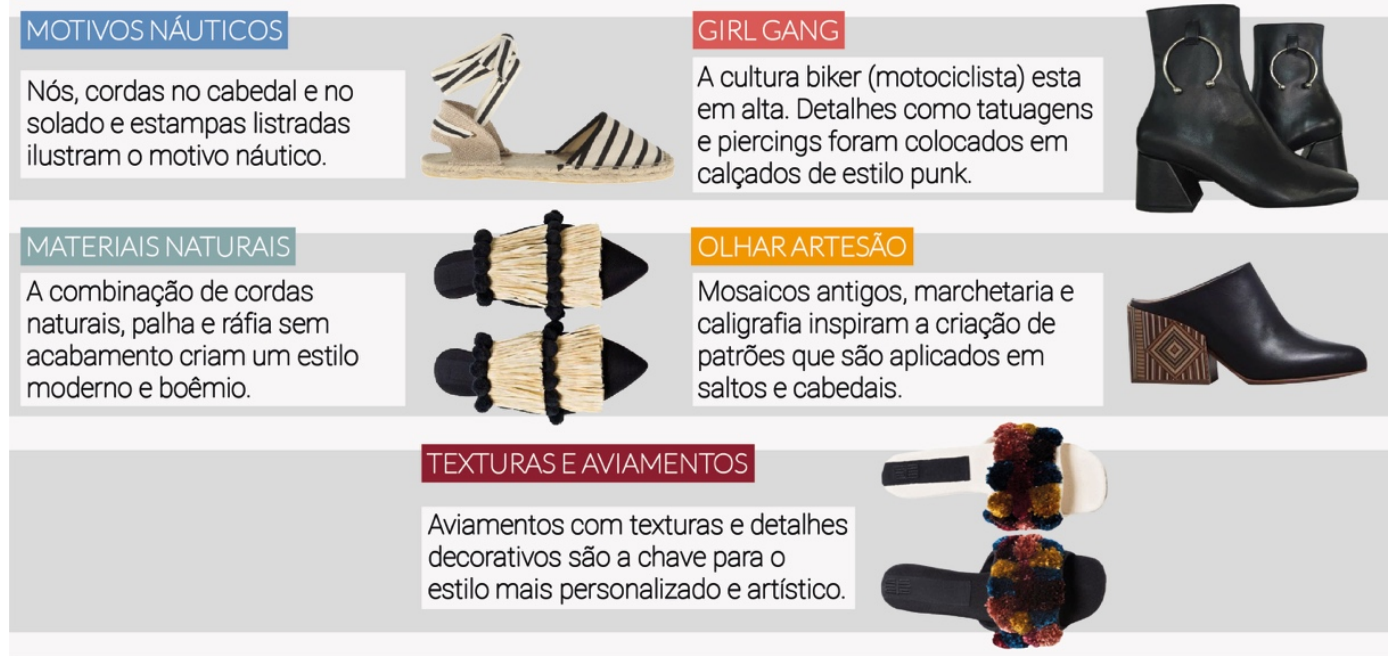

Fonte: Os autores com base em WGSN, 2016

Em relação aos modelos de calçados para o verão 2018 (Figura 5), os tipos mais usados foram focados no conforto e versatilidade como: mocassim, mule, mary-jane, sandália com cordas, sapatilha, espadrilles, ankleboots e sneaker sandal (WGSN, 2016).

Figura 5 - Modelos de calçado para Kindship

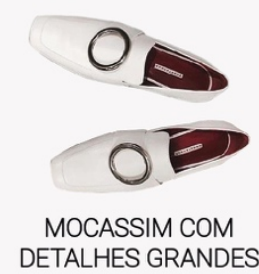

EM METAL

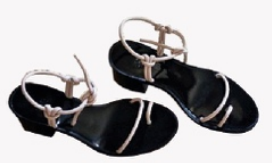

SANDÁLIA COM CORDAS ATADAS

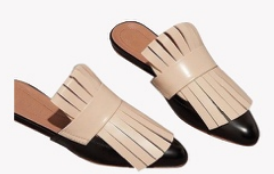

MULE COM BICO ARREDONDADO

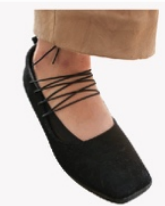

SAPATILHAS COM MODELOS DOBRÁVEIS E FITAS REMOVIVIEIS

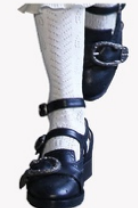

MARY-JANE COM MÚLTIPLAS TIRAS

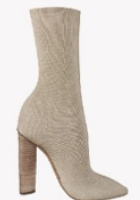

ANKLEBOOTS COM MATERIAIS ELÁSTICOS

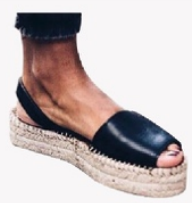

ESPADRILLES COM

PLATAFORMA E

CORDAS EM RÁFIA

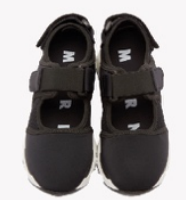

SNEAKER SANDAL -

TENDÊNCIA

ATHLEISURE

Fonte: Os autores com base em WGSN, 2016 


\subsection{Processo de criação do calçado para joanete}

\subsubsection{Brainstorm}

Para a geração de alternativas foram aplicadas técnicas criativas, que são ferramentas com objetivo de auxiliar na geração de ideias. Com base nos requisitos de projeto, foi elaborado um brainstorm (Figura 6) organizado em um diagrama com o objetivo de sintetizar, dividir, formar ideias e relações entre o produto em si e seus componentes.

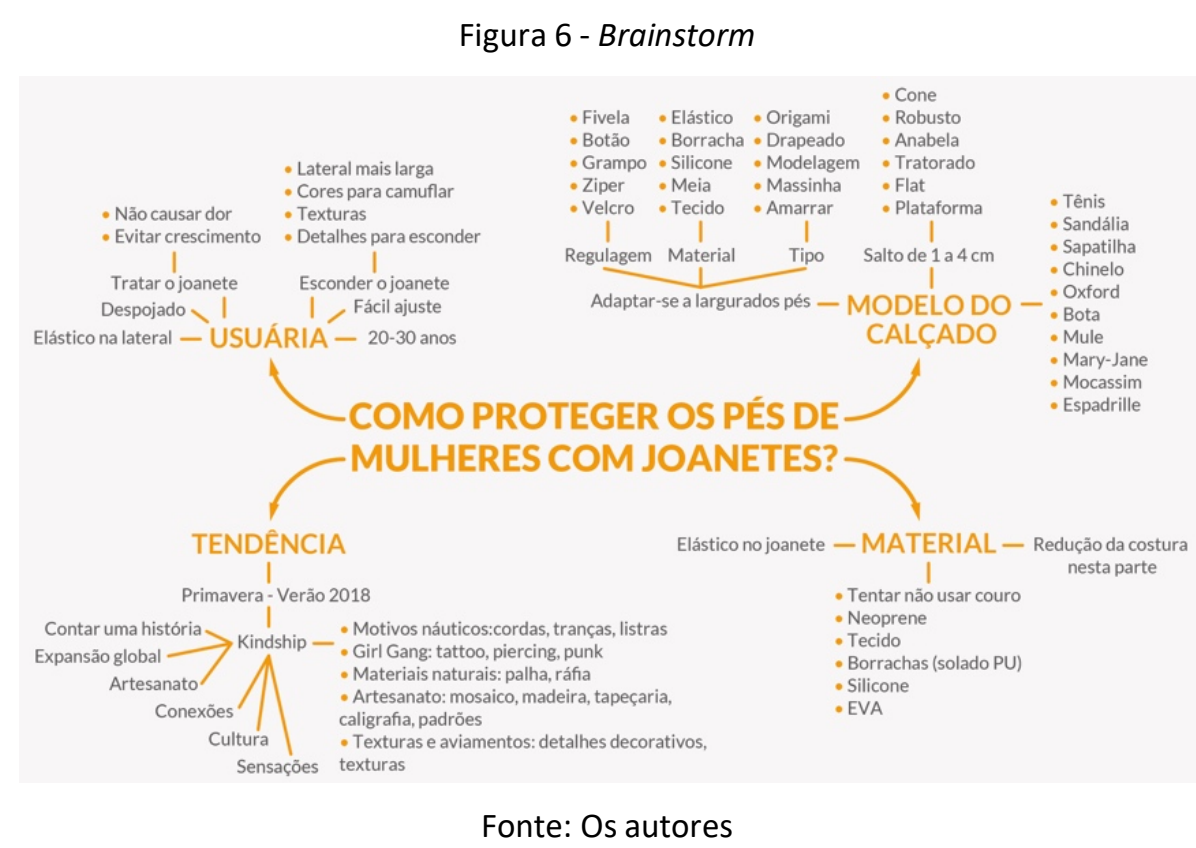

Tendo como base a pergunta: como proteger os pés de mulheres com joanetes?, foi possível definir os pontos chave relacionados aos usuários, modelos do calçado, tendências e materiais. Para os usuários, o calçado deveria possuir elasticidade na lateral, esconder o joanete, possuir fácil ajuste e ser desenvolvido para o público feminino. Os calçados também deveriam se adaptar a largura dos pés pelo uso de regulagens ou materiais elásticos. Por sua vez, estes modelos de calçados também deveriam possuir salto baixo, entre 1 a $4 \mathrm{~cm}$, e ter a parte da lateral do joanete coberta. Deste modo, alguns modelos de calçados listados que cumpriam estes quesitos foram: tênis, sandália, sapatilha, bota e mocassim.

As tendências foram seguidas para o verão de 2018 conforme os relatórios da WGSN, sendo que das temáticas analisadas, foi escolhido o Kindship para servir de inspiração estética para este projeto. Esta tendência possuía como fontes de inspiração os motivos náuticos, materiais naturais, artesanato e detalhes decorativos com texturas e aviamentos.

Por fim, os materiais usados na fabricação do calçado deveriam possuir elasticidade para se adaptar ao formato do joanete. Estes materiais listados foram: neoplex, tecido, borracha, silicone e EVA.

\subsubsection{Geração de alternativas}

As primeiras alternativas foram geradas por ilustração manual (Figura 7). 
Figura 7 - Primeiros desenhos das alternativas

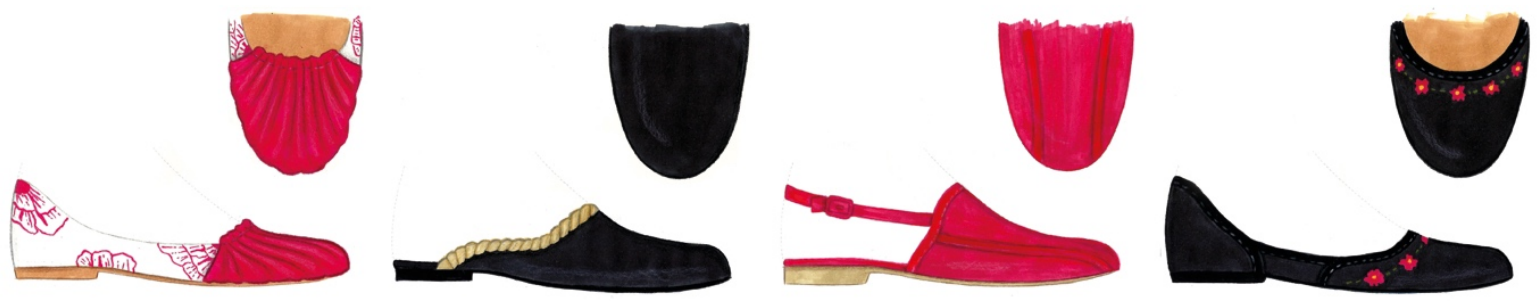

Fonte: Os autores

Outras alternativas foram geradas por protótipos funcionais com o intuito de analisar sua possível fabricação (Figura 8). Os materiais usados na produção foram: couro sintético, tecido em algodão, neoplex e veludo. As palmilhas, solados, contrafortes e couraças foram pré-fabricados e a montagem foi feita com base no processo de fabricação real de calçados.

Figura 8 - Alternativas geradas por protótipos
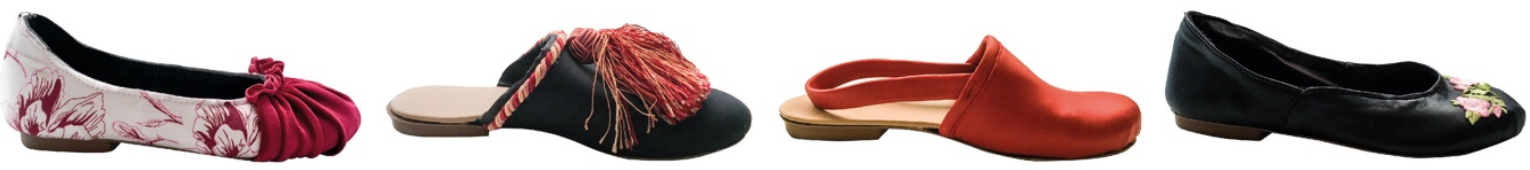

Fonte: Os autores

A geração destes primeiros protótipos foi importante para experimentar materiais, formas e tipos de acabamento. Além disso, estes modelos também foram necessários para aprimorar as técnicas de fabricação de calçados, uma vez que os protótipos finais também seriam feitos à mão.

Durante o desenvolvimento das alternativas, notou-se que a maioria dos modelos de calçados seguiram os requisitos de projeto. Deste modo, devido a variedade de modelos de calçados gerados que poderiam adequar-se a este projeto, foi escolhida uma alternativa que possui formas mais simplificadas e características que podem ser adaptadas a diferentes tipos de detalhes na região do joanete, que tem como objetivo camuflar o mesmo.

A alternativa selecionada foi uma sapatilha de bico redondo e salto baixo escolhida por ser um dos modelos de calçados mais usados pelas usuárias, conforme as entrevistas e questionários. Do mesmo modo, este tipo de calçado também foi apontado como tendência para o verão de 2018, com base na WGSN (2016).

O desenho curvilíneo (1) do modelo de calçado para mulheres com joanete foi projetado para encaixar-se melhor nos pés. Como detalhamentos técnicos, o modelo de sapatilha criado possui cinco partes no cabedal ${ }^{1}$ : forro (2), viés (3), cabedal anterior (4), cabedal posterior (5) e camada interna em neoplex (6). O forro foi constituído de uma peça única em couro sintético com apenas uma costura vertical no calcanhar. Já o viés foi composto de uma tira de tecido que contornou o calçado conferindo acabamento para o mesmo. O cabedal anterior foi feito em material elástico com camada interna em neoplex que se adaptou aos dimensionamentos do

\footnotetext{
${ }^{1}$ Parte que está acima da sola. Ele é feito de peças de molde que são costuradas juntas.
} 
joanete. Para dar maior resistência e segurança durante a marcha, o cabedal posterior foi feito em um material menos elástico. O solado da sapatilha selecionada possui salto de $1,5 \mathrm{~cm}$ (7) e assim como a palmilha (8), possui largura mais ampla para acomodar o pé com joanete. As vistas lateral, superior e explodida da alternativa escolhida podem ser vistas na Figura 9.

Figure 9 - Vistas lateral, superior e explodida da alternativa escolhida

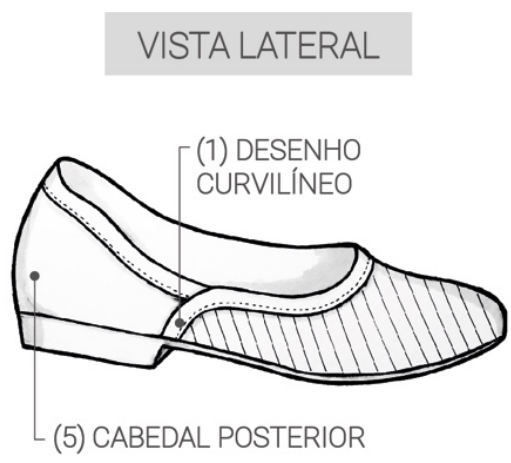

(5) CABEDAL POSTERIOR

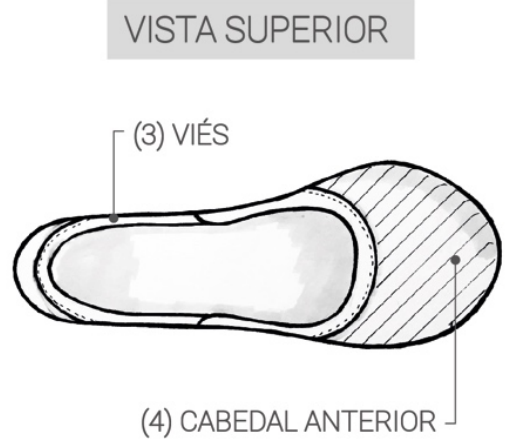

Fonte: Os autores

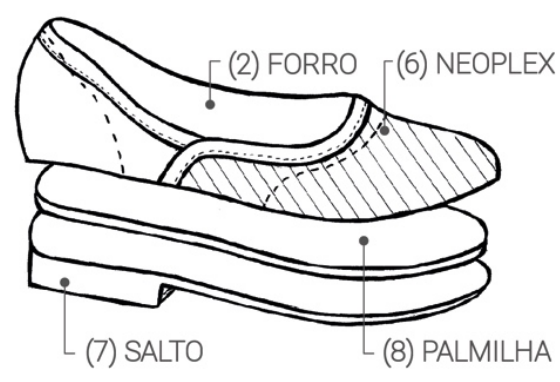

(8) PALMILHA

\section{4 Ênfase estética no desenvolvimento do modelo de calçado para mulheres com joanete}

Foram geradas três alternativas do modelo base de sapatilha desenvolvidas com estética diferenciada por aviamentos e cores, a fim de dar maior opção de escolha para os usuários (Figura 10). O modelo em pompom, o modelo pérola e o modelo bordado foram desenvolvidos para serem um diferencial dos calçados. Além disso, estes detalhes também tiveram a função de esconder e camuflar o joanete, atraindo a atenção para toda a parte anterior do cabedal e não somente para a sua lateral.

Figura 10 - Modelos de calçado para mulheres com joanete
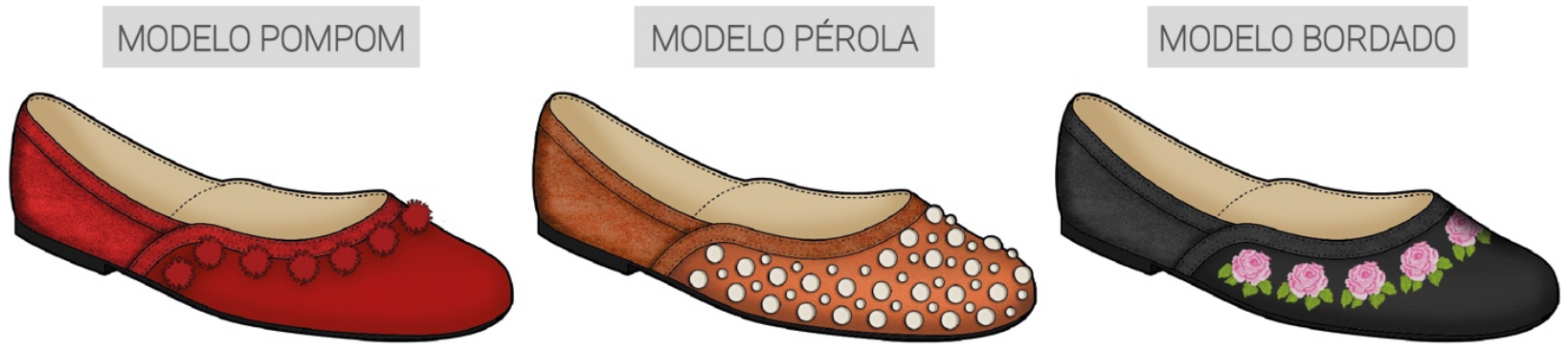

Fonte: Os autores

Estes três modelos também foram escolhidos com base nas tendências. Segundo a tendência Kindship para o verão de 2018, o uso de elementos artesanais como o pompom de lã, a pérola e o bordado foram muito valorizados por representar as singularidades do trabalho manual e da cultura artística com adornos personalizados e detalhes delicados.

As cores escolhidas foram baseadas na paleta cromática da Kindship. Deste modo, optouse por usar os tons de vermelho amora e laranja abóbora por remeterem-se a elementos quentes, fortes e versáteis combinados com uma opção neutra do preto marinho (Figura 11). 
Figura 11 - Paleta de cores selecionada

Além da variação de cores, os destaques destas alternativas foram os aviamentos. Estes detalhes foram escolhidos para cumprir o requisito de camuflar o joanete e chamar a atenção para toda a parte anterior do cabedal e não somente para a região da deformação, o que poderá reduzir o constrangimento dos pés das usuárias. Outra justificativa para a escolha destes aviamentos foi a adequação com a tendência Kindship pelo uso de elementos artesanais, como o pompom de lã, bordado e pérola. Estes componentes deram textura e diferenciação aos calçados e expressaram os pontos principais da tendência escolhida, como a exaltação do artesanato e mistura de superfícies e cores, como mostra painel da Figura 12.

Figura 12 - Painel com tendências escolhidas com base na Kindship
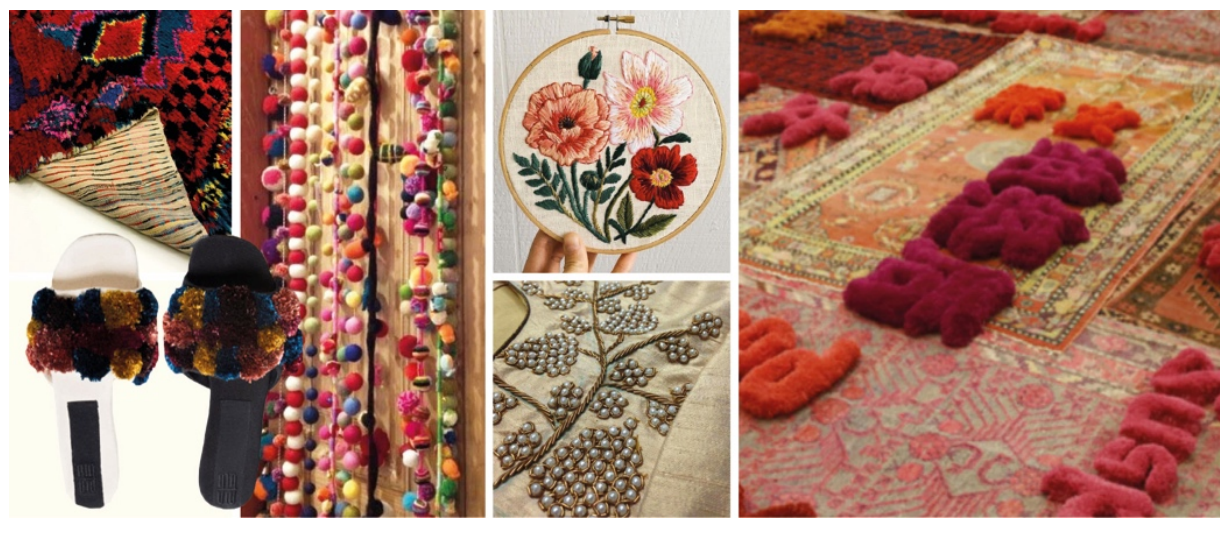

Fonte: Os autores

Em seguida, os modelos de calçado para mulheres com joanete foram gerados por protótipos funcionais com base nos detalhamentos da alternativa nos três modelos propostos: pompom, pérola e bordado, como mostram as Figuras 13, 14, 15 e 16.

Figura 13 - Modelos dos calçados em bordado e pompom

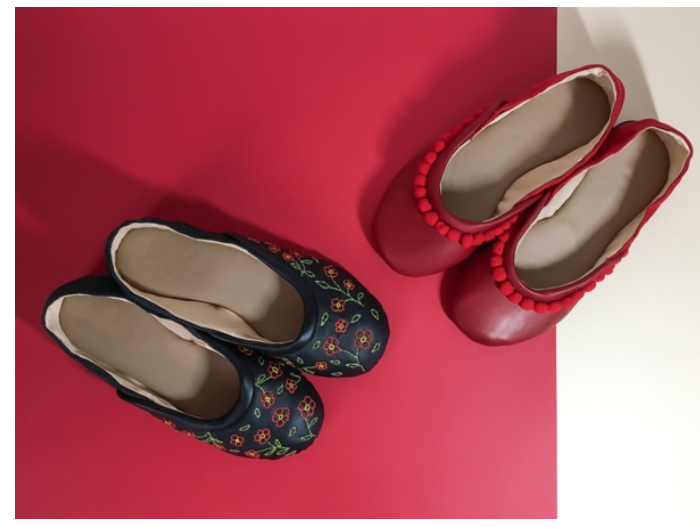

Os autores
Figura 14 - Modelo do calçado em pérola

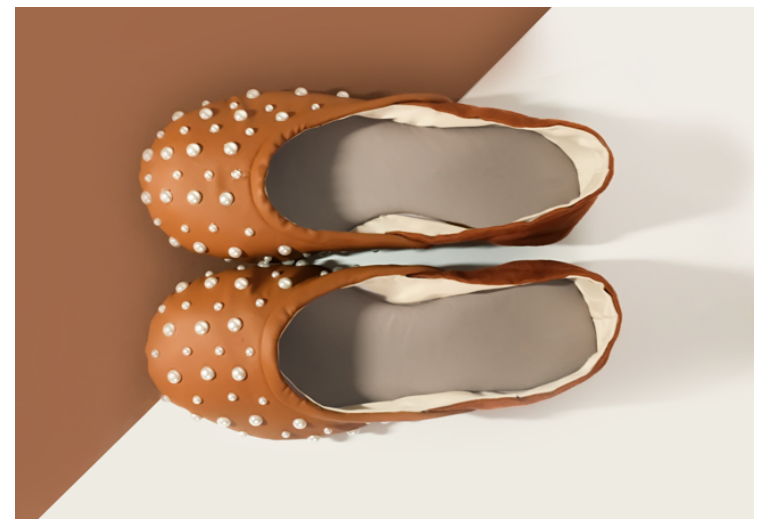

Os autores 
Figura 15 - Modelos do calçado e pé com joanete
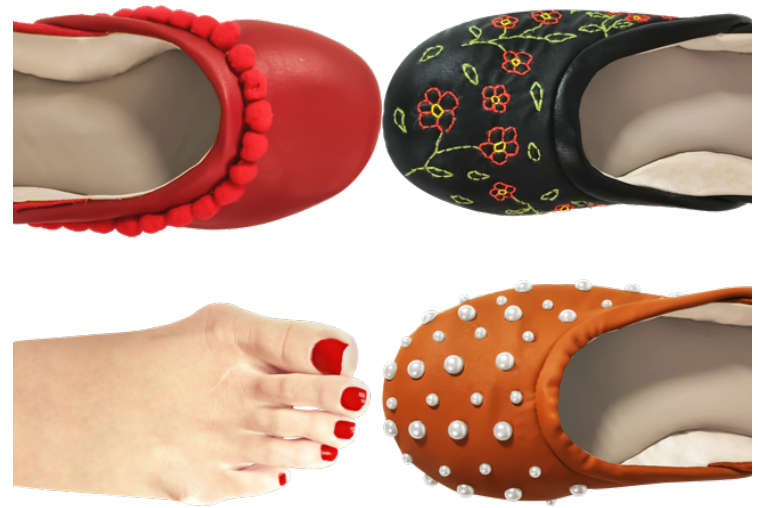

Os autores
Figura 16 - Mockup dos modelos

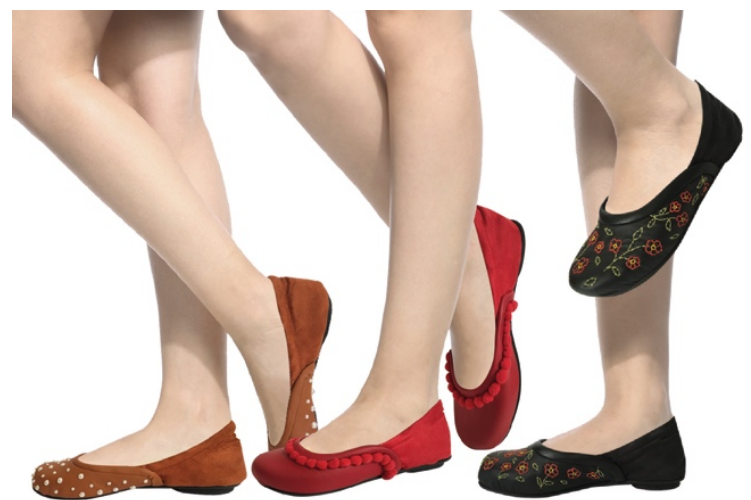

Os autores

\section{Resultados}

Com o intuito de verificar se os modelos de calçado para joanete estavam de acordo com os requisitos do usuário para a estética, listados em Takayama, Merino e Merino (2017), foi elaborada um checklist (Tabela 2).

Tabela 2 - Checklist

\begin{tabular}{ll}
\hline \multicolumn{1}{c}{ REQUISITOS DO USUÁRIO - ESTÉTICA } & \multicolumn{1}{c}{ MODELOS DE CALÇADO PARA JOANETE } \\
\hline Possuir estética agradável adequada às tendências & $\begin{array}{l}\sqrt{ } \text { Possui tendências para o verão 2018, especificamente } \\
\text { da tendência Kindship. }\end{array}$ \\
\hline $\begin{array}{l}\text { Camuflar o joanete para evitar o constrangimento } \\
\text { causado por esta deformação }\end{array}$ & $\begin{array}{l}\sqrt{ } \text { Detalhes de pompom, bordado e pérola no cabedal } \\
\text { frontal chama a atenção para toda a parte anterior do } \\
\text { cabedal, não somente para a região da deformação, } \\
\text { camuflando o joanete. }\end{array}$ \\
\hline $\begin{array}{l}\text { Ser um modelo de tênis, sapatilha ou bota, para ter } \\
\text { maior aceitação dos usuários }\end{array}$ & $\begin{array}{l}\checkmark \text { É um modelo de sapatilha, que também é tendência o } \\
\text { verão de } 2018\end{array}$ \\
\hline
\end{tabular}

Fonte: Os autores

Pela tabela, observou-se que os modelos de calçado para joanete, desenvolvidos na presente pesquisa, estavam de acordo com os requisitos do usuário em relação à estética.

Os modelos criados possuíam como base estética as tendências para o verão 2018, especificamente a temática Kinship, pelo uso de aviamentos artesanais como o pompom, pérola e bordado e paleta cromática desta tendência. Deste modo, o requisito "possuir estética agradável adequada às tendências", foi contemplado por esta pesquisa.

Na sequência, o requisito "camuflar o joanete para evitar o constrangimento causado por esta deformação" foi cumprido ao utilizar os detalhes de pompom, bordado e pérola no cabedal para chamar a atenção para toda esta parte e não para o joanete em si, camuflando o mesmo.

Por fim, o calçado desenvolvido foi um modelo de sapatilha que estava de acordo com as tendências para o verão 2018 e fazia parte do requisito: ser um modelo de tênis, sapatilha ou bota, para ter maior aceitação dos usuários. 


\section{Conclusão}

Mulheres com hálux valgo têm como um dos fatores de surgimento e agravamento da deformação o uso de calçados inadequados, deste modo, a escolha do produto adequado para este tipo de pé é essencial para evitar dores, desconforto e o aumento do joanete. Neste sentido, a abordagem participativa e Design Centrado no Usuário podem reduzir os erros de projeto e melhorar a aceitação e satisfação do usuário.

Como objetivo, a presente pesquisa desenvolveu um calçado para mulheres com joanete com o intuito de adequá-lo aos requisitos estéticos dos usuários com base no Design Participativo, Design Centrado no Usuário e tendências para o verão 2018.

Durante o desenvolvimento do projeto, o propósito de integrar o Design Participativo e Centrado no Usuário ocorreu pela aplicação de questionários e entrevistas. Esta abordagem levantou dados importantes sobre as necessidades reais dos usuários que resultou na geração de uma tabela de requisitos.

Como a presente pesquisa teve ênfase nos requisitos estéticos dos usuários, principalmente no requisito: possuir estética agradável adequada às tendências, foi elaborado um estudo de tendências com base nos relatórios da WGSN que identificou temáticas, cores, conceitos e detalhes para o verão 2018.

O desenvolvimento do calçado para joanete foi elaborado com o uso da técnica criativa brainstorm que ajudou na síntese e formação de ideias sobre o produto. Na geração de alternativas foram elaboradas ilustrações manuais e protótipos funcionais que foram importantes para a experimentação de materiais, formas e acabamentos, além do aprimoramento das técnicas de fabricação de calçados.

Como resultado do objetivo do projeto, foi selecionado um modelo de sapatilha básica com desenho curvilíneo fabricada com forro em couro sintéticos, viés de acabamento, materiais elásticos no cabedal, camada interna em neoplex, salto baixo com 1,5 cm e palmilha com largura mais ampla para ser mais adequada aos pés com joanete.

Com base no modelo de sapatilha selecionado, foram elaboradas três alternativas com estética diferenciada por aviamentos e cores. Como diferencial destes modelos, os detalhes no cabedal do calçado foram desenvolvidos para esconder e camuflar o joanete, atraindo a atenção para toda a parte anterior do cabedal e não somente para a sua lateral, o que poderá reduzir o constrangimento dos pés das usuárias.

Pela diversidade de modelos propostos, mais usuárias poderão encontrar um modelo que esteja mais adequado às suas necessidades. Do mesmo modo, a presente pesquisa deixou como alternativa a aplicação de detalhes no cabedal frontal do calçado para a camuflagem do joanete, podendo esta solução ser aplicada em outros modelos de calçados e outros tipos de aviamentos.

Pelo checklist, foi possível notar que o modelo de calçado estava adequado aos requisitos. $\mathrm{Na}$ continuação, pretende-se melhorar a qualidade dos protótipos dos modelos para elaborar testes com usuárias e diagnosticar se a estética do calçado estava realmente de acordo com as suas necessidades. Com o resultado, será possível refinar o modelo inicialmente proposto ou elaborar novos modelos de calçado em futuros desdobramentos. 


\section{Agradecimentos}

À Coordenação de Aperfeiçoamento de Pessoal de Nível Superior (CAPES), à Universidade Federal de Santa Catarina (UFSC), ao Núcleo de Gestão de Design \& Laboratório de Design e Usabilidade (NGD-LDU) e ao Hospital Universitário Polydoro Ernani de São Thiago por viabilizarem a presente pesquisa.

\section{Referências}

CAMARGO, Liriane Soares de Araújo; FAZANI, Alex Jose. Explorando o Design Participativo como Prática de Desenvolvimento de Sistemas de Informação. Incid: Revista de Ciência da Informação e Documentação, [s.l.], v. 5, n. 1, p.138-150, 25 mar. 2014. Universidade de Sao Paulo Sistema Integrado de Bibliotecas - SIBiUSP. http://dx.doi.org/10.11606/issn.2178-2075.v5i1p138-150.

CASE, Thomas A.. Os Pés Brasileiros. 2012.

CRABTREE, Andy. Designing Collaborative Systems: A Practical Guide to Ethnography. Londres: Springer, 2003.

DORR, Bill. Understanding and Using Emerging Aesthetic Design Trends. 2017. Disponível em: $<$ https://www.appliancedesign.com/articles/95306-understanding-and-using-emerging-aestheticdesign-trends>. Acesso em: 08 mar. 2017.

ENDSLEY, Mica R.; BOLTÉ, Betty; JONES, Debra G.. Designing for situation awareness: an approach to user-centered design. Georgia: Crc Press, 2003.

GOLDCHER, A.. Podologia. 5. ed. São Paulo: Roca, 2009.

GOONETILLEKE, Ravindra Stephen. The Science of Footwear. Florida: CRC Press, 2012.

MERINO, Giselle Schmidt Alves Díaz. GODP - Guia de Orientação para Desenvolvimento de Projetos: Uma metodologia de Design Centrado no Usuário. Florianópolis: Ngd/ Ufsc, 2016. Disponível em: <www.ngd.ufsc.br>. Acesso em: 21 fev. 2018.

ROSENFIELD, Kathrin H.. Estética. [s. L.]: Zahar, 2006.

SOUZA, Talita; HELD, Maria Silvia Barros de. A Estética como Conforto Psicológico na Moda. D: Vii Colóquio de Moda, 2011.

TAKAYAMA, Leticia; MERINO, Giselle Schmidt Alves Diaz; MERINO, Eugenio Andres Diaz. Desenvolvimento De Um Calçado Para Mulheres Com Joanete: Uma Abordagem Centrada No Usuário. In: ERGODESIGN - Congresso Internacional De Ergonomia E Usabilidade De Interfaces Humano Tecnológica: Produto, Informações Ambientes Construídos E Transporte, 16., 2017, Florianópolis. Anais. Florianópolis: Blucher Proceedings, 2017. p. 1094 - 1099.

TYRRELL, Wendy; CARTER, Gwenda. Therapeutic Footwear: A Comprehensive Guide. [s. L.]: Churchill Livingstone, 2009.

VARELLA, Antônio Drauzio. Joanete (Hallux Valgus Ou Hálux Valgo). 2014. Disponível em: $<$ https://drauziovarella.com.br/doencas-e-sintomas/joanete-hallux-valgus-ou-halux-valgo/>. Acesso em: 01 fev. 2018.

WORTH GLOBAL STYLE NETWORK. Future Trends. Disponível em: <www.wgsn.com>. Acesso em: 18 out. 2016. 